\title{
Toward a unified semantics for English either*
}

\author{
William C. Thomas \\ Ohio State University
}

\begin{abstract}
This paper proposes that the additive and disjunctive uses of English either share a semantic core. Formulated in Inquisitive Semantics, this core involves a requirement that either apply to an inquisitive proposition, which accounts for either's co-occurrence with disjunction. It also includes an additive presupposition that is more flexible than has previously been assumed in the literature, which allows the analysis to account for novel data in which additive either conveys that a proposition is unexpected or undesirable. The inability of either to appear in alternative questions is also pointed out and accounted for.
\end{abstract}

Keywords: additives, discourse particles, inquisitive semantics

\section{Introduction}

English either has several uses, which have so far been treated as attributable to distinct lexical items. The disjunctive use, shown in (1-a), occurs only in the presence of disjuncts joined with or and precedes the first disjunct. The additive use, shown in (1-b), always occurs in clause-final position, is a negative polarity item (NPI), and has sometimes been taken to be the negative counterpart of too. The determiner use, shown in (1-c), can either precede a noun or occur without one.
a. We're either going to LA or to New York.
b. We're not going to New York, either. ${ }^{1}$
c. We're not going to either (city).
(Rullmann 2002)

Disjunctive use
Additive use
Determiner use

Previous semantic research on either (e.g Rullmann 2003; Levinson 2008; Ahn 2015) has focused on the additive use and has not attempted to relate the semantics

* I would like to thank Ashwini Deo for intense and stimulating discussion of this research. Very useful feedback was also provided by five anonymous reviewers for SALT 31 and the members of the OSU Synners and Pragmatics discussion groups. I am also grateful to participants of SALT 31 for their thoughtful questions and comments.

1 Rullmann (2002) also points out the existence of what he calls FP-Disj either: We're not going to LA, or to New York either. Though he argues that this use is diachonrically distinct, I assume that in modern English it is a syntactic variant of the additive use and will ignore it for simplicity's sake. 
of these uses even though they are diachronically related (see Rullmann 2002) and exhibit certain similarities in behavior.

A striking similarity between the uses is that they can all be taken to co-occur with disjunction. This is most obvious for the disjunctive use, which occurs only in the presence of overt disjunction, as shown in (2-a). The additive use, as noted by Ahn (2015), seems to require the conjunction of two negated propositions and therefore can be taken to involve the negation of a conjunction (since $\neg p \wedge \neg q=\neg(p \vee q)$ for any propositions $p$ and $q$ ). Thus We're not going to $L A$, and we're not going to New York, either has the same truth conditions as We're not going to LA or New York, as shown in (2-b). The example of determiner either in (1-c) similarly seems to involve a negated disjunction, as shown in (2-c).

(2) a. We're either going to LA or to New York.

= We're going to LA or New York.

LA $\vee N Y$

b. We're not going to LA, and we're not going to New York, either. $=$ We're not going to LA or New York.

$\neg(\mathrm{LA} \vee \mathrm{NY})$

c. I haven't visited either city. = I haven't visited LA or New York.

This paper proposes that the additive and disjunctive uses of either share a semantic core that accounts for their co-occurrence with disjunction and resolves a number of other puzzles. I leave the analysis of the determiner use for future work. I begin by summarizing the existing semantic research on either in Section 2 before presenting data in Section 3 that challenges those analyses. The main puzzle to be solved regarding additive either is that it can be used felicitously in contexts that do not provide the kind of antecedent that either has been assumed to require, namely a focus alternative of its host sentence or a partial answer to the Question Under Discussion. The disjunctive use also exhibits behavior in need of an explanation: When it occurs in a question, that question cannot be interpreted as an alternative question. In Section 4, I make use of Inquisitive Semantics (see e.g. Ciardelli, Groenendijk \& Roelofsen 2019) to propose a unified analysis for the additive and disjunctive uses that provides solutions to these puzzles.

\section{Background}

I follow Kripke (2009/1990), Heim (1992), and many others in assuming that additive particles including either and too are anaphoric on a salient antecedent. Kripke (2009/1990) points out that (3), where ${ }_{F}$ indicates focus, requires that there be a salient person other than Sam who is eating dinner in New York tonight. Kripke argues against the presupposition of too simply being existential (i.e., that someone is eating dinner in New York tonight) because (3) is infelicitous out of the blue even 
though it is obviously true that many other people besides Sam are eating dinner in New York tonight. ${ }^{2}$

(3) Tonight $[\mathrm{Sam}]_{F}$ is having dinner in New York, too.

Work on additive either (e.g. Rullmann 2003; Ahn 2015) has often assumed that the antecedent must be a focus alternative of either's host sentence. Focus alternatives are generated by replacing the focused material in a sentence with other expressions of the same semantic type (see Rooth 1985, 1992). In (4), for instance, the antecedent I don't like [pizza $]_{F}$ is a focus alternative of the host sentence I don't like [spaghetti $]_{F}$.

(4) I don't like $[\mathrm{pizza}]_{F}$, and I don't like [spaghetti $]_{F}$, either. (Rullmann 2003)

Rullmann (2003) argues that additive either scopes under negation and proposes that sentences of the form $\alpha$ either presuppose that there is a contextually salient focus alternative of $\alpha$ that is false. ${ }^{3}$ In (4), for example, we have $\alpha=I$ like spaghetti, and so the additive presupposition is satisfied by the fact that the salient focus alternative I like pizza is false.

According to Ahn (2015), on the other hand, $\alpha$ either disjoins $\llbracket \alpha \rrbracket$ with a salient antecedent proposition. Her proposal is shown in (5), which says that given a salient antecedent proposition $q$ from the context and a proposition $p$ from the host sentence, a sentence containing either presupposes that a focus alternative of $p$ is true and asserts the disjunction $q$ or $p$. Following Rullmann, she assumes that either scopes under negation, so the negation in (4) applies to the disjunction of I like spaghetti and I like pizza. Thus I don't like spaghetti, either, when uttered in (4), has the truth conditions of I don't like spaghetti or pizza.

$$
\llbracket \text { either } \rrbracket(q)(\llbracket p \rrbracket \sim C)=\lambda w: q \in C-\left\{\llbracket p \rrbracket^{\mathrm{o}}\right\} \cdot q_{w} \vee \llbracket p \rrbracket^{w}
$$

Beaver \& Clark (2008) sketch an analysis of additive particles within Roberts' (1996) theory of discourse, which assumes that every utterance addresses some Current Question Under Discussion (which may be implicit). They suggest that the focus sensitivity of additives is due to a presupposition that the Current Question (CQ) has been partially answered by a salient proposition in the common ground that is not entailed by the additive's prejacent (i.e., the proposition that is the additive's argument). A partial answer to a question $Q$ is a proposition that entails the negation of at least one possible answer to $Q$. In (4), for example, the CQ is What don't

2 See Szabolcsi (2017) and Ruys (2015) for dissenting opinions.

3 Pointing out that the associate of too or either bears a rising accent, Krifka (1998) argues that the associate is a contrastive topic rather than a focus. In response, Rullmann (2003) proposes that too and either associate with an F-marked trace. I will set this issue aside for the purposes of this paper. 
Toward a unified semantics for English either

you like?, and I don't like pizza provides a partial answer to that question, thereby satisfying the additive presupposition.

(6) CQ: What don't you like?

a. Partial answer: I don't like [pizza $]_{F}$.

b. I don't like [spaghetti $]_{F}$, either.

The meaning of disjunctive either is less well-studied than the meaning of additive either. A few authors (e.g. McCawley 1993; Nicolae \& Sauerland 2016) have noted that disjunctive either is often associated with an inference that the disjunction is exclusive. The sentence We're going either to LA or to New York, for example, gives rise to the inference that we are not going both to LA and to New York. Nicolae \& Sauerland (2016) demonstrate experimentally that in at least some contexts, sentences of the form either $p$ or $q$ do indeed convey $\neg(p \wedge q)$ more strongly than disjunctions without either do. They take this exclusive inference to be obligatory for disjunctive either and attribute it to an exhaustification operator in the lexical meaning of either. Naturally-occurring data provide evidence, however, that the exclusive inference can, in fact, be cancelled.. In (7-a) and (7-b), for example, the exclusive inferences are cancelled by maybe both. I therefore concur with McCawley's (1993: 316-317) argument that the exclusive inference is a Gricean conversational implicature and therefore not part of the lexicalized meaning of either.

(7) a. This [unknown subject] believes that the men he's targeting have harmed him, either physically or psychologically, maybe both.

b. His head spun and he felt like he was going to either pass out or drown. Maybe both.

$(\mathrm{COCA})^{4}$

\section{Data}

The additive and disjunctive uses of either both exhibit behavior that previous analyses have not accounted for. We shall see that the data militate in favor of an additive presupposition that is more flexible than the ones that have previously been proposed. Disjunctive either also has a puzzling profile, failing to be licensed in disjunctive questions that are interpreted as alternative questions.

4 COCA $=$ Corpus of Contemporary American English (Davies 2008-) 
Thomas

\subsection{The additive use}

Naturally-occurring data show that previous approaches to the additive presupposition are too restrictive: Additive either often occurs in contexts in which there is no salient antecedent that can be construed as a focus alternative of the host sentence or as a partial answer to the CQ. Some examples are shown in (8). In (8-a), there is no antecedent that can be construed as a focus alternative of the host sentence not because of societal pressures, nor is that sentence an answer to a question that has already been partially answered. A canonical additive presupposition would require there to be some other salient reason besides societal pressures that is not the reason for the couples staying married (e.g. It wasn't because of the financial benefits, and it wasn't because of societal pressures, either). But this is not the case in (8-a). The context in (8-b) similarly lacks this kind of antecedent.

(8) a. I can name at least a half dozen now-dead couples...who've worked and succeeded in the same fields in my country and yet somehow managed to stay married. And not because of societal pressures either.

b. Most of the paratroopers that landed didn't have nothing. I was one of them. [The leg bag] tore right off because we jumped at speeds of 150 miles an hour maybe even higher. [...] And lower than we should've been. That wasn't bad either, because you got to the ground quicker.

(COCA)

While a Beaver \& Clark-style analysis posits that the antecedent and host sentence of either are partial answers to the same CQ, the host sentences in (8) do not address the same question as their antecedents. Instead, each of them seems to address a new, implicit question that becomes salient after the utterance of the antecedent. I will refer to the question addressed by the antecedent as the Antecedent Question (abbreviated AQ); the AQ is the CQ at the time of utterance of the antecedent. In what follows, I will use "CQ" to refer to the CQ at the time of utterance of the host sentence of either, which is typically an accommodated question rather than an explicitly uttered one. Following Krifka (1998), I assume that either and other clause-final additive particles in English are always focused and that this amounts to focus on the clause's polarity, evoking the set of focus alternatives $\{p, \neg p\}$ for any prejacent $p$. This makes such a clause congruent to the polar question whether $p$, so that question should be taken to be the CQ of any sentence in which additive either appears in the main clause (see also Goodhue to appear for discussion of polarity focus). I therefore take the discourses in (8) to have the structures shown in (9). A satisfactory analysis of either needs to account for the fact that, contra what has been assumed in the literature, the antecedent and host sentences need not address the same question. 
Toward a unified semantics for English either

a. AQ: Did the couples manage to stay married?

Antecedent: They managed to stay married.

CQ: Was it because of societal pressures that they stayed married?

(i) It wasn't because of societal pressures, either.

b. AQ: How high were you when you jumped?

Antecedent: Lower than we should've been.

CQ: Was it bad that you were lower than you should've been?

(i) It wasn't bad either.

Another fact in need of explanation is that in these examples either seems to interact with expectations in a particular way: (9-a-i) conveys that societal pressures were the expected reason for the couples to stay married, and (9-b-i) conveys that jumping from too low was expected to be bad. Thus the sentences containing either contradict a proposition that is expected to be true given that the antecedent is true. In other words, the antecedent implicates the negation of either's host sentence.

Either can also appear in host sentences that are desired rather than expected. Thus either is acceptable not only in (10-a), where the speaker expected Frank not to attend the party, but also in (10-b), where the speaker desired that Frank not attend the party. The acceptability of either is degraded in contexts where the host sentence is neither unexpected nor undesired, which is the case in (10-c).

(10) a. Context: Frank doesn't like parties, so he doesn't often attend them, and when he does, he always leaves early.

(i) Frank was at the party tonight, and he didn't leave early, either!

b. Context: The speaker doesn't like Frank and tries to minimize the amount of time they spend with him.

(i) Frank was at the party tonight, and he didn't leave early, either!

c. Context: Frank is always the life of the party. He always stays until the very end, and the speaker always looks forward to seeing him.

(i) Frank was at the party tonight, and he didn't leave early, (\#either)!

It is also worth noting that the antecedents, too, in (9-a-i), (9-b-i), and (10) express an unexpected proposition: It is unexpected that the couples stayed married (which is conveyed by the verb managed), it is unexpected that jumping from too low wasn't bad, and it is unexpected that Frank went to a party. The fact that the antecedents are unexpected seems to be what allows either to appear in these examples even though the antecedents do not contain any kind of overt negation, contra what has been assumed by Rullmann (2003) and Ahn (2015).

In each of the corpus examples in (8), the host sentence of either presupposes its antecedent: Not because of societal pressures presupposes that the couples stayed married, and That wasn't bad either presupposes that the paratroopers did indeed 
jump from too low. In general, however, the host sentence need not presuppose the antecedent, as demonstrated by the examples in (11), where She hasn't studied on the exam does not presuppose that Morgan did incredibly well on the exam, and Jane isn't rich does not presuppose that Jane owns a Lamborghini. In (11) we see the same counter-expectational effect that we saw in (9) and (10) : In light of the fact that Morgan did incredibly well on the exam, it is unexpected that she has not studied. Similarly, given that Jane owns a Lamborghini, it is surprising that she is not rich. In each case, the antecedent implicates the negation of the host sentence.

a. AQ: How did Morgan do on the exam?

(i) Morgan did incredibly well on the exam. She hasn't studied all semester, either.

b. AQ: What kind of car does Jane own?

(i) Jane owns a Lamborghini! She isn't rich, either.

For the garden-variety additive use studied by Beaver \& Clark (2008), Rullmann (2003), Ahn (2015), and others, rather than taking the antecedent and host sentence to both address the same CQ, I take the host sentence to address a subquestion ${ }^{5}$ of the AQ, on the aforementioned assumption that the host sentence of either addresses a polar question. This is illustrated in (12).

AQ: What don't you like?

Antecedent: I don't like pizza.

CQ: Do you like spaghetti?

a. I don't like spaghetti, either.

The generalization to be drawn from the above data is that in contexts where additive either is found, there is always some salient question-sometimes the AQ, sometimes the CQ - to which both the antecedent and host sentence either entail or implicate at least a partial answer. For the garden-variety additive use, that salient question is the AQ: The antecedent entails a partial answer to the AQ, and the host sentence also does since the CQ is a subquestion of the AQ. For the counterexpectational use in (9) and (11), the salient question is the CQ: The antecedent in each of those examples implicates an answer to the CQ, and the host sentence entails an answer to it. A new additive presupposition will be proposed in Section 4 to account for this generalization.

5 A question $Q_{1}$ is a subquestion of a question $Q_{2}$ if and only if every proposition that completely answers $Q_{2}$ also completely answers $Q_{1}$. See Roberts 1996. 
Toward a unified semantics for English either

\subsection{The disjunctive use}

The disjunctive use of either also has a puzzling profile that so far has not been extensively probed in the literature. As noted in Section 2, I take disjunctive either to have no truth-conditional effect: The (a) sentences in (13) and (14) are truthconditionally equivalent to the corresponding (b) sentences. Note that unlike the additive use, the disjunctive use is not sensitive to the polarity of its host sentence, appearing under negation in (14) but not in (13).

(13) a. You're either a Lacoste person or you're a Fred Perry person.

b. You're a Lacoste person or you're a Fred Perry person. (COCA)

(14) a. You can not build either financial or economic stability on an unsound monetary system.

b. You can not build financial or economic stability on an unsound monetary system.

(COCA)

It is worth noting that although either typically appears in the presence of two disjuncts, it can also occur with three or more disjuncts, as shown in (15).

a. I'm getting either this or iPhone 5 or Droid DNA.

b. The rest of the current frame bodies either suck at ISO, framerate, video, or audio focus.

(COCA)

The main puzzle to be addressed with regard to the disjunctive use is the fact that questions in which it appears cannot be interpreted as alternative questions. Disjunctive questions can receive either a polar or alternative question interpretation, depending on their prosody (see Ciardelli et al. 2019: 77-79). The question in (16), for example, where the arrows indicate rising intonation on math and falling intonation on physics, is an alternative question and requires either math or physics as an answer; yes and no are infelicitous responses. If that question is instead uttered with a single rising intonational contour, as in (17), then it is interpreted as a polar question and can be answered with Yes or No.

(16) Alternative question: Does Jesse study math ${ }^{\uparrow}$ or physics ${ }^{\downarrow}$ ?

a. Math.

b. \#Yes.

(17) Polar question: Does Jesse study math or physics $^{\uparrow}$ ?

a. Yes. 
Interestingly, when either appears in a disjunctive question, only the polar question interpretation is available. Thus (18) can always be answered with yes or no, while math might be a slightly odd response since it seems to provide more information than the asker requested.

Does Jesse study either math or physics?

a. Yes.

b. ?Math.

This property of disjunctive either needs an explanation. In the analysis that follows, I propose that it can be accounted for by a requirement that either appear within the scope of the issue-cancelling projection operator ! of Inquisitive Semantics.

\section{Analysis}

Before proposing an analysis of the facts laid out in the previous section, I describe the key features of Inquisitive Semantics, which provides a straightforward way of accounting for either's sensitivity to disjunction.

\subsection{Inquisitive Semantics}

I adopt the formulation of Inquisitive Semantics laid out by Ciardelli et al. (2019). The key innovation of Inquisitive Semantics is the notion of an issue, which is a downward-closed set of information states (sets of worlds). Propositions in Inquisitive Semantics are identified with issues. In particular, the semantic content of a declarative sentence that does not contain disjunction or existential quantification is the set containing the set of worlds in which the sentence is true, as well as all the subsets of that set. An example is shown in (19), where $|\phi|$ is shorthand for the set of worlds in which $\phi$ is true.

a. $\llbracket$ Cameron invited Jordan $\rrbracket=\{s|s \subseteq|$ Cameron invited Jordan $\mid\}$ $=\{\mid$ Cameron invited Jordan $|$,$| Cameron invited only Jordan \mid$, |Cameron invited only Jordan and Skyler|, |Cameron invited only Jordan, Taylor, and Bailey $\mid, \ldots\}$

The issue in (19) has a single maximal element, namely the set of worlds in which Cameron invited Jordan. An issue's maximal elements are called its alternatives. Issues with more than one alternative are said to be inquisitive.

Inquisitive issues can be created by disjoining two propositions. Propositions are disjoined by taking the union of the corresponding issues, as shown in (20), where the union results in an issue with two alternatives corresponding to the two disjuncts. 
Toward a unified semantics for English either

The set of alternatives in an issue is called its inquisitive content, while the union of all the information states contained in an issue is called its informative content.

$$
\begin{aligned}
& \llbracket \text { Cameron invited Jordan or Taylor } \rrbracket \\
& =\llbracket \text { Cameron invited Jordan } \rrbracket \cup \llbracket \text { Cameron invited Taylor } \rrbracket \\
& =\{s|s \subseteq| \text { Cameron invited Jordan } \mid\} \cup\{s|s \subseteq| \text { Cameron invited Taylor } \mid\} \\
& =\{s|s \subseteq| \text { Cameron invited Jordan } \mid \text { or } s \subseteq \mid \text { Cameron invited Taylor } \mid\}
\end{aligned}
$$

One benefit of Inquisitive Semantics for the present analysis is that either's cooccurrence with disjunction will be able to be accounted for by a requirement that its argument be an inquisitive proposition.

Both declarative and interrogative sentences are taken to denote issues. The meaning of a question is the issue whose alternatives are the weakest information states that would fully answer the question. These information states are said to resolve the issue. Thus the meaning of Does Bailey like pizza?, shown in (21), is the issue whose maximal elements are the set of worlds in which Bailey likes pizza and the set of worlds in which Bailey does not like pizza.

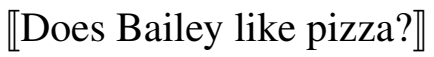

$$
=\{s|s \subseteq| \text { Bailey likes pizza } \mid \text { or } s \subseteq \mid \text { Bailey does not like pizza } \mid\}
$$

Thus questions and disjunctive assertions both express inquisitive issues. Ciardelli et al. (2019) assume that in English, sentences that express inquisitive issues are always interpreted as questions. To prevent disjunctive declaratives from being interpreted as questions, Inquisitive Semantics provides an issue-cancelling projection operator, written!, which converts any inquisitive proposition into a non-inquisitive proposition with the same informative content. It does this by taking the set complement twice, as shown in (22).

\section{Issue-cancelling projection operator: $! P=P^{* *}$}

I assume that ! is applied at the end of the derivation of the meaning of every declarative sentence, even if the issue expressed is non-inquisitive.

Inquisitive Semantics also provides an info-cancelling projection operator, written ?, which takes any proposition $P$ and trivializes its informative content by joining $P$ with the complement of $P$. The result is always an inquisitive proposition.

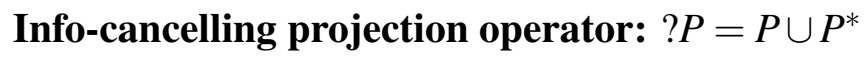

? is used to derive the meaning of polar questions. An example is shown in (24), where the meaning of Does Bailey like pizza? is obtained by applying ? to the meaning of Bailey likes pizza. 
Conversational contexts are generally taken to include a set of Questions Under Discussion that the interlocutors wish to answer (see Roberts 1996; Ginzburg 1996). In Inquisitive Semantics, a context can be represented by a single issue that results from merging all of the issues representing those questions (Ciardelli et al. 2019: 31-32). In the analysis that follows, however, it will be necessary to distinguish between open issues in the context rather than collapsing them into a single issue.

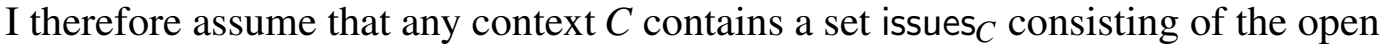
issues that the interlocutors intend to resolve (cf. Ciardelli et al. 2019: 31).

\subsection{The semantic core of either}

I propose that an operator EITHER is involved in the meaning of both disjunctive and additive either. EITHER has the following properties:
a. EITHER is an operator over propositions. ${ }^{6}$
b. $\operatorname{EITHER}(P)$ requires that $P \neq ! P$
c. EITHER is licensed only within the scope of !.
d. $\operatorname{EITHER}(P)$ entails $P$; EITHER makes no at-issue contribution.

The requirement in (25-b) ensures that the prejacent of either always contains at least two alternatives, which accounts for either's co-occurrence with disjunction. We will see in Section 4.3 that (25-c) accounts for the fact that either does not occur in alternative questions.

Although either does not make any at-issue contribution, it of course carries an additive presupposition. As we have seen, existing accounts of that presupposition are too restrictive, so in Section 4.4 I propose a new one that I argue provides greater empirical coverage. This presupposition will turn out to also be satisfied by the disjunctive use, allowing for a unified analysis of the additive and disjunctive uses.

\subsection{The disjunctive use}

The meaning of disjunctive either is simply EITHER. (25-b) ensures that the argument of either always contains at least two alternatives. Thus (26-a), with only one

6 This is a slight oversimplification. Either in fact seems to be polymorphic since additive either is licensed by the quantifiers no and few (e.g. Few people have been to space, and few dogs have either.) As argued by Rullmann (2003), either must take scope under its licensor, so its argument cannot be a proposition in such sentences. With an appropriate semantic type for either, it should be possible to derive the meanings of such sentences using the compositional Inquisitive Semantics of Ciardelli, Roelofsen \& Theiler (2017), but due to space constraints I cannot do so here. 
alternative, is illicit, but (26-b), with two, is acceptable. As noted in Section 3.2, either can also combine with propositions that have more than two alternatives, as in (26-c). This is permitted by (25-b), which does not place an upper bound on the number of alternatives in either's prejacent.

a. \#We're going to either New York.

$\operatorname{EITHER}(N Y)$

b. We're going to either New York or LA.

$\operatorname{EITHER}(N Y \vee L A)$

c. We're going to either New York, LA or DC. EITHER $(N Y \vee L A \vee D C)$

The satisfaction of requirement (25-c) is always guaranteed in declarative sentences since it is assumed that ! is always applied at the end of the derivation of a declarative sentence. (25-c) does, however, correctly restrict the interpretation of questions containing disjunctive either. Such questions can only be interpreted as polar questions because only the polar question interpretation, according to Ciardelli et al. (2019), contains !. These two interpretations of a disjunctive question containing either are shown in (27), where $m$ is the proposition that Jesse studies math, and $p$ is the proposition that Jesse studies physics. In the derivation of the polar question interpretation, ! merges the two alternatives into one, and then ? joins the result with its negation, yielding an inquisitve proposition whose alternatives are Jesse studies math or physics and Jesse does not study math or physics. The alternative question interpretation, on the other hand, is derived by simply disjoining Jesse studies math with Jesse studies physics, so ! is not present to license EITHER. ${ }^{7}$

a. Polar question:

Does Jesse study either math or physics ${ }^{\uparrow} ? \quad$ ?! $\quad$ EITHER $\left.(m \vee p)\right)$

b. Alternative question:

Does Jesse study (*either) math ${ }^{\uparrow}$ or physics ${ }^{\downarrow}$ ? $\quad m \vee p$

7 The ruling out of the alternative question interpretation would also be accomplished if ! were actually part of the meaning of either, converting every prejacent of either into a non-inquisitive proposition. The interaction of either with modals provides evidence against this approach, however. Aloni (2007) argues that modals quantify over the alternatives that or introduces within their scope. Possibility modals such as may in (i), for example, perform universal quantification over these alternatives, which accounts for the fact that both (i-a) and (i-b) entail that Vincent may be in Paris and Vincent may be in London. If ! were part of the meaning of either, then those alternatives would not be available for may to quantify over in (i-b). With a reformulation of Aloni's analysis in Inquisitive Semantics, the present analysis of either correctly derives the meaning of (i-b), but for reasons of space I must omit the details here.

(i) a. Vincent may be in Paris or London.

b. Vincent may be in either Paris or London. 


\subsection{The additive use}

I adopt Ahn's (2015) proposal that additive either is anaphoric on a salient proposition $q$ retrieved from the context, which is disjoined with the proposition $p$ (which I will call the prejacent) that appears under the scope of negation (or another NPI licenser) in either's host sentence. I propose that EITHER applies to that disjunction. For example, in (28-a) the prejacent I like spaghetti is disjoined with I like pizza, which is made salient by the antecedent I don't like pizza. EITHER then applies to the result, which satisfies (25-b) since the disjunction produces a proposition with two alternatives. Negation scopes over either, and then ! is applied at the end of the derivation of every declarative sentence, satisfying (25-c). The sentence in (28-a) therefore has the truth conditions of I don't like pizza or spaghetti.

Antecedent: I don't like pizza.

a. I don't like spaghetti, either.

(i) $\quad p=$ I like spaghetti, $q=$ I like pizza

$! \neg \operatorname{EITHER}(q \vee p)$

In (28), the proposition $q$ is salient because it is overtly present within the antecedent. However, the proposition to be disjoined with the prejacent can instead be salient by virtue of being a salient expectation or desire. In (29), for example, $q$ does not appear in the antecedent but is nonetheless salient because the couples were expected not to stay married (which is conveyed by the verb managed). If such an expectation were not salient, then $q$ would not be available to be disjoined with $p$. Similarly, the proposition Frank did not attend the party is available to be disjoined in the argument to either in (30) as long as it is expected in the context.

(29) Antecedent: The couples managed to stay married.

a. It wasn't because of societal pressures, either. $\quad \neg \operatorname{EITHER}(q \vee p)$ "It is not the case that the couples either split up or stayed together because of societal pressures."

(i) $\quad p=$ It was because of societal pressures.

(ii) $q=$ The couples did not stay married.

(30) Antecedent: Frank went to the party last night.

a. He didn't leave early, either. $\quad \neg \operatorname{EITHER}(q \vee p)$

"It is not the case that Frank either did not go to the party last night or left it early."

(i) $\quad p=$ Frank left the party early.

(ii) $q=$ Frank did not attend the party. 
Toward a unified semantics for English either

\subsubsection{The additive presupposition}

We have seen that existing accounts of either's presupposition are empirically inadequate: In many contexts, the antecedent is neither a focus alternative of the prejacent nor a partial answer to the CQ. I propose that either carries the presupposition in (31), where $\Rightarrow$ is an implicational relationship with Kratzer's $(1981 ; 1986 ; 1991)$ modal semantics for conditionals, which can be either an entailment or a weak implication, as in Toosarvandani 2014. This presupposition can be seen as a generalization of the Beaver \& Clark additive presupposition: Whereas they propose that the antecedent of an additive particle is presupposed to be a partial answer to the CQ, (31) states that the antecedent of either implicates (not necessarily entails) at least a partial resolution to some salient open issue in the context (not necessarily the CQ).

Additive presupposition of either: Given a context $C$, a prejacent proposition $p$, an antecedent proposition $q_{0}$, and a proposition $q$ made salient by $q_{0}$, EITHER $(q \vee p)$ presupposes that there is an issue $Q \in$ issues $_{C}$ such that:

a. $\quad p$ is at least a partial resolution to $Q$, and

b. there exists a proposition $q^{\prime}$ such that $q_{0} \Rightarrow q^{\prime}$ and $q^{\prime}$ is at least a partial resolution to $Q$.

For the garden-variety additive use of either, the salient unresolved issue $Q$ is the AQ. The antecedent $q_{0}$ and the prejacent $p$ each trivially implicate a partial resolution to $Q$ by virtue of actually being a partial resolution. In (32), for example, $Q$ is What don't you like?, and the antecedent I don't like pizza and the prejacent $I$ like spaghetti are both partial resolutions to that question, so (31) is satisfied. ${ }^{8}$

$$
\begin{aligned}
& Q=\text { What don't you like? } \\
& q_{0}=\text { I don't like pizza. }\left(=q^{\prime}\right) \\
& \text { a. I don't like spaghetti, either. } \quad(p=\text { I like spaghetti. })
\end{aligned}
$$

When either is used in contexts where its prejacent does not partially resolve the $\mathrm{AQ}$, such as the contexts given in (8) and (11), the salient unresolved issue $Q$ is the CQ. In those cases (31) is satisfied because $q_{0}$ weakly implicates a resolution $q^{\prime}$ to

8 Additive either can also occur in questions, such as the naturally-occurring question in (i) provided by Rullmann (2003). The salient unresolved issue in this case is a superquestion of the host question, and the prejacent of either is a partial resolution to that issue, as required by (31). For reasons of space I must leave a full analysis of the use of either in questions to future work.

(i) $Q=$ Who would give Clinton a fair trial?

$q_{0}=$ The Republicans didn't give Clinton a fair trial.

a. Would the Democrats have, either?

(cf. Rullmann 2003) 
the CQ, while $p$ is a resolution to the CQ.

$q_{0}=$ The couples managed to stay married. $(\Rightarrow$ They stayed married because of societal pressures.)

$Q=$ Was it because of societal pressures?

a. It wasn't because of societal pressures, either.

( $p=$ It was because of societal pressures.)

$q_{0}=$ Jane owns a Lamborghini! ( $\Rightarrow$ Jane is rich.)

$Q=$ Is Jane rich?

a. She isn't rich, either.

( $p=$ She is rich.)

The additive presupposition in (31) is also satisfied by the disjunctive use. Since the disjunctive use does not involve anaphora, the "antecedent" can be taken to simply be one of the disjuncts, and so $q_{0}=q$. Each of the two disjuncts will either entail or implicate a a partial resolution to the CQ, as in (35) and (36). This additive presupposition therefore allows us to maintain a unified analysis of the additive and disjunctive uses; it is not a special presupposition of the additive use, but rather a part of the core meaning shared between the two uses. The difference between the two uses is that one of the disjuncts in the argument to additive either is anaphorically retrieved from the context, while the two disjuncts in the argument to disjunctive either are both contained in the host sentence.

CQ: Where are we going?

a. We're going to either LA or New York. $q_{0}=q=$ We're going to New York.

$p=$ We're going to LA.

(36) CQ: Did Sasha go to class today?

a. She either went to class or was sick.

$q_{0}=q=$ Sasha was sick. $\Rightarrow$ Sasha did not go to class.

$p=$ Sasha went to class.

\subsubsection{How either interacts with expectations}

It remains to be explained why the prejacent, not its negation, must be implicated by the antecedent in those contexts where additive either occurs in a host sentence that does not partially resolve the AQ. The presupposition in (31) would be satisfied if the antecedent implicated the negation of the prejacent instead, yet this seems to be impossible. For example, since Jane owns a Lamborghini implicates Jane is rich, (37-a) is felicitous but (37-b) sounds quite odd. Since the prejacent always appears under negation or another NPI licensor, the result is the counter-expectational effect 
Toward a unified semantics for English either

that we have observed: The fact that Jane is not rich defies expectations.

a. Jane owns a Lamborghini! She's not rich, either.

b. Jane owns a Lamborghini! She's not poor, (\#either).

I argue that this counter-expectational effect is not a lexically encoded effect of either but rather is attributable to general principles of discourse coherence. I make use of Onea's $(2013 ; 2016)$ notion of a potential question (PQ). A PQ is a question that is raised by an utterance and can become the CQ addressed by a subsequent utterance. Onea (2016) defines PQs as in (38), where $\models_{\text {def }}$ is a defeasible entailment relation and $\mathscr{H}(q)$ is the set of highlighted alternatives ${ }^{9}$ in $q$, and $\downarrow$ indicates downward closure.

Potential question: A PQ $q$ licensed by some utterance $u$ in some context $c$ is such that: $c \cap \llbracket u \rrbracket \models$ def $p$ and $c \not \neq_{\text {def }} p$, where $p=\operatorname{info}(\mathscr{H}(q))^{\downarrow}$, and there is no $p^{\prime} \in \mathscr{H}(q)$ such that $c \cap \llbracket u \rrbracket \models p^{\prime}$.

(Onea 2016: 127)

What (38) says is that a PQ $q$ is licensed by an utterance $u$ in a context $c^{10}$ if $c$ updated with $u$ defeasibly entails that there exists a true answer to $q$ among $q$ 's highlighted alternatives but does not entail any particular highlighted alternative, and $c$ alone does not defeasibly entail that there is a true highlighted alternative.

In addition to PQs, Onea (2016: 142) introduces the notion of a derived potential question (DPQ), which is a question that has the same alternatives as some PQ but whose highlighted alternative(s) are desired or preferred by the speaker rather than defeasibly entailed by $c \cup \llbracket u \rrbracket$. For example, (39-b) is a PQ triggered by (39-a) because John is expected to have died if he had a massive stroke. (39-c), on the other hand, is a DPQ because it is desirable for John to have survived.

a. John had a massive stroke yesterday.

b. Did he die?

9 The highlighted alternatives in a $w h$-question are the alternatives produced by replacing the $w h$-word with appropriate individuals, and the highlighted alternative in a polar question is the alternative that is explicitly mentioned in the question (Roelofsen \& van Gool 2010). Illustrative examples are shown in (i), with the highlighted alternatives underlined.

(i) a. Is John happy?

b. Who is happy?

1) Alternatives: $\{$ John is happy, Max is happy, ..., Nobody is happy. $\}$

10 As is standard in Inquisitive Semantics, the context $c$ here is a single issue whose informative content is the common ground and whose inquisitive content is the result of merging all the open issues in the context. 
I assume that asking a potential question, asking a derived potential question, and asking a subquestion of an open question are the only licit discourse moves that can be used to raise issues. I assume that each of these types of questions can also be accommodated. ${ }^{11}$ The key difference between the garden-variety additive use and the counter-expectational use of either is that the CQ of the former is a subquestion of the AQ, while the CQ of the latter is a PQ triggered by the antecedent. (Again, typically the CQ will be accommodated rather than explicitly asked.) Illustrative examples are shown in (40).

a. AQ: What don't you like?

Antecedent: I don't like pizza.

CQ: Do you like spaghetti?

subquestion of AQ

(i) I don't like spaghetti, either.

b. AQ: Where did Frank go last night?

Antecedent: Frank went to a party.

CQ: Did he leave the party early?

PQ licensed by antecedent

(i) He didn't leave early, either.

As noted in Section 3.1, (40-b-i) is felicitous in a context where Frank is expected to leave the party early. It is also acceptable if the speaker desired for Frank to leave early. If neither of these two conditions holds, however, then either sounds odd in (40-b-i). This is what now needs to be explained. The additive presupposition proposed in (31) does not explain it since if Frank were expected not to leave early, that would still mean that an answer to the CQ is implicated by the antecedent. I claim that the reason (40-b) requires the expectation or desire that it does is that the CQ of (40-b-i) must be a PQ or DPQ triggered by its antecedent, since clearly it cannot be a subquestion of the AQ. To be a PQ, its highlighted answer (He did leave early) must be defeasibly entailed ${ }^{12}$ by Frank went to a party, which is the case if Frank is expected to leave parties early. To be a DPQ, its highlighted answer must be desired by the speaker. If the highlighted answer is neither expected nor desired, then Did he leave the party early? cannot be accommodated as the CQ.

This analysis crucially hinges on the fact that the CQ of a sentence ending with additive either is always a polar question. A wh-question can also be a potential question, as is the case in (41), where Why did they stay married? is a potential

11 Onea (2016: 350-354) actually argues that subquestions cannot be accommodated. To avoid complicating the present analysis, I will not take up that idea here.

12 I take defeasible entailment to be equivalent to $\Rightarrow$ with a stereotypical ordering source; hence the defeasible entailment of the prejacent by the antecedent contributes to the satisfaction of both the definition of a PQ and the proposed additive presupposition. 
question because there must be a reason that the couples stayed married. If this question could be accommodated as the CQ of an either-containing sentence, then (41-a) would be felicitous even though financial benefits are not expected to be the reason for the couples to stay together. The oddness of either in (41-a) is due to the fact that focus on either signals that the CQ is a polar question and must therefore be Was it because of financial benefits?, but that question is not licensed as a PQ because its highlighted answer is not defeasibly entailed by the antecedent in that context. As explained in Section 3.1, the evidence that the CQ is indeed a polar question is the fact that additive either is always focused, but the question of why exactly additive either is required to bear focus is one I must leave to future work.

(Couples are expected to stay married only due to societal pressures.)

AQ: Did the couples manage to stay married?

Antecedent: They did manage to stay married.

CQ: Why did they stay married?

(PQ licensed by antecedent)

a. It wasn't because of the financial benefits, (\#either).

\section{Conclusion}

This analysis of either provides a shared semantic core for the additive and disjunctive uses, unifying them for the first time, and it also provides greater empirical coverage than previous analyses of either. By making the additive presupposition more flexible, it is able to account for the counter-expectational use of either, which has not been previously analyzed. It also accounts for the fact the either prevents disjunctive questions from being analyzed as alternative questions. Future research may be able to unify the determiner use with these uses.

A puzzle that has not been discussed here due to space constraints is the fact that additive either is a negative polarity item with an unusual distribution. Additive either occurs primarily in downward-entailing contexts. This is to be expected on any analysis that, like this one, adopts Ahn's (2015) proposal that additive either disjoins a proposition with an antecedent because in positive contexts, that disjunction is uninformative. This can be seen in (42).

(42) We're going to LA. \#We're going to New York, either.

"We're going to New York or LA."

(uninformative)

There are certain downward-entailing environments that fail to license either, such as the antecedents of conditionals and the restrictor of no and every. The reasons for this have not been fully elucidated: Existing accounts of either's licensing (Rullmann 2003; Levinson 2008; Ahn 2015) are not able to predict its exact distribution. Future work should explain why either has only the licensers it does. 
Thomas

\section{References}

Ahn, Dorothy. 2015. The semantics of additive either. Sinn und Bedeutung 19 20-35.

Aloni, Maria. 2007. Free choice, modals, and imperatives. Natural Language Semantics 15. 65-94. doi:10.1007/s11050-007-9010-2.

Beaver, David I. \& Brady Z. Clark. 2008. Sense and Sensitivity: How Focus Determines Meaning. Malden, MA: Blackwell.

Ciardelli, Ivano, Jeroen Groenendijk \& Floris Roelofsen. 2019. Inquisitive Semantics. Oxford: Oxford University Press.

Ciardelli, Ivano, Floris Roelofsen \& Nadine Theiler. 2017. Composing alternatives. Linguistics and Philosophy 40. 1-36. doi:10.1007/s10988-016-9195-2.

Davies, Mark. 2008-. The Corpus of Contemporary American English (COCA): 560 million words, 1990-present. https://corpus.byu.edu/coca/.

Ginzburg, Jonathan. 1996. Dynamics and the semantics of dialogue. In Jerry Seligmann \& Dag Westerståhl (eds.), Logic, Language, and Computation, vol. 1, 221-237. Stanford, CA: CSLI Publications.

Goodhue, Daniel. to appear. All focus is contrastive: On polarity focus, answer focus, contrastive focus, and givenness. Journal of Semantics https://ling.auf. net/lingbuzz/004205.

Heim, Irene. 1992. Presupposition projection and the semantics of attitude verbs. Journal of Semantics 9. 183-221. doi:10.1093/jos/9.3.183.

Kratzer, Angelika. 1981. The notional category of modality. In Hans J. Eikmeyer, Hannes Rieser \& Peter Rolf Luzeier (eds.), Words, Worlds, and Contexts: New Approaches to Word Semantics, 38-74. Berlin: Walter de Gruyter. doi:10.1515/9783110842524-004.

Kratzer, Angelika. 1986. Conditionals. Chicago Linguistic Society (CLS) 22(2). $1-15$.

Kratzer, Angelika. 1991. Modality. In Arnim von Stechow \& Dieter Wunderlich (eds.), Semantik: Ein Internationales Handbuch der zeitgenössischen Forschung, Berlin: Walter de Gruyter. doi:10.1515/9783110126969.7.639.

Krifka, Manfred. 1998. Additive particles under stress. Semantics and Linguistic Theory (SALT) 8. 111-128. doi:10.3765/salt.v8i0.2799.

Kripke, Saul A. 2009. Presupposition and anaphora: Remarks on the formulation of the projection problem. Linguistic Inquiry 40(3). 367-386. doi:10.1162/ling.2009.40.3.367. Transcript of a talk delivered at the conference "Linguistic and Philosophical Approaches to the Study of Anaphora", Princeton University, 1990.

Levinson, Dmitry. 2008. Licensing of negative polarity particles yet, anymore, neither, and either: Combining downward monotonicity and assertivity. Palo 
Toward a unified semantics for English either

Alto, CA: Stanford University Phd dissertation.

McCawley, James D. 1993. Everything that Linguists Have Always Wanted to Know about Logic... But Were Ashamed to Ask. Chicago: University of Chicago Press 2nd edn.

Nicolae, Andreea C. \& Uli Sauerland. 2016. A contest of strength: or versus either-or. Sinn und Bedeutung 20. 551-568.

Onea, Edgar Gáspár. 2013. Potential questions in discourse and grammar. Göttingen, Germany: University of Göttingen Habilitation.

Onea, Edgar Gáspár. 2016. Potential Questions at the Semantics-Pragmatics Interface. Leiden: Brill.

Roberts, Craige. 1996. Information structure in discourse. OSU Working Papers in Linguistics 49. 91-136.

Roelofsen, Floris \& Sam van Gool. 2010. Disjunctive questions, intonation, and highlighting. Amsterdam Colloquium 17. 384-394. doi:10.1007/978-3-64214287-1_39.

Rooth, Mats. 1985. Association with focus. Amherst, MA: University of Massachusetts at Amherst Phd dissertation.

Rooth, Mats. 1992. A theory of focus interpretation. Natural Language Semantics 1. 75-116. doi:10.1007/BF02342617.

Rullmann, Hotze. 2002. A note on the history of either. Chicago Linguistics Society (CLS) 38 111-126.

Rullmann, Hotze. 2003. Additive particles and polarity. Journal of Semantics 20(4). 329-401. doi:10.1093/jos/20.4.329.

Ruys, E.G. 2015. On the anaphoricity of too. Linguistic Inquiry 46(2). 343-361. doi:10.1162/ling_a_00184.

Szabolcsi, Anna. 2017. Additive presuppositions are derived through activating focus alternatives. Amsterdam Colloquium 21. 455-464.

Toosarvandani, Maziar. 2014. Contrast and the structure of discourse. Semantics and Pragmatics 7. 1-57. doi:10.3765/sp.7.4.

William C. Thomas

300 Oxley Hall

1712 Neil Ave.

Columbus, $\mathrm{OH} 43210$

thomas.3846@osu.edu 